\title{
Salvage Therapy for Prostate Cancer: Which is Best? Brachytherapy versus Open and Robotic Prostatectomy
}

\section{Sanchia Goonewardene*}

Guys and St Thomas' NHS Foundation Trust, London, West Midlands United Kingdom

\begin{abstract}
No standard salvage therapy exists. The objective of salvage therapy is oncological control with minimum toxicity. Advances in functional imaging, including multi parametric prostate MRI and abdominopelvic lymphangio$\mathrm{MRI}$, have paved the way for salvage therapy in localised recurrence. To date there are no randomized clinical trials comparing HDR-BT with radical prostatectomy.
\end{abstract}

Methods: We conduct as retrospective review over 20 years comparing outcomes of salvage brachytherapy compared to open and robotic radical prostatectomy, searching Embase and Medline.

Results: Whilst robotic radical prostatectomy is a clear winner, there is also a role for salvage brachytherapy.

Conclusions: The role of salvage therapies such as brachytherapy need to be further explored.

Keywords: Salvage brachytherapy; Oncological; Functional outcomes; Salvage robotic prostatectomy; Salvage open prostatectomy

\section{Introduction}

At least one third of patients who receive external beam radiation will have biochemical recurrence (BCR) with 9 and $7 \%$ having local and distant failure, respectively [1,2]. Approximately $20 \%-30 \%$ of men with clinically localized prostate cancer treated with radiation therapy will develop evidence of biochemical recurrence (BCR) [3]. The vast majority of men with $\mathrm{BCR}$ after radiation therapy are managed with observation of androgen deprivation therapy (ADT). Only $10 \%$ of men are curatively treated using salvage local therapy [3].

\section{Methods}

We conduct as retrospective review over 20 years comparing outcomes of salvage brachytherapy (SBRACH) compared to open (SORP) and robotic radical prostatectomy (SRARP), searching embase and medline. Search terms used include salvage therapy and brachytherapy or prostatectomy (open or robotic).

\section{Results}

The goal of SRARP is to cure radiation-recurrent prostate cancer and cancer-specific survival. This approaches $80 \%$ at 10 years [3]. In a recently published multicentre review of outcomes after SRARP, men with a pre-SRARP PSA of $4 \mathrm{ng} / \mathrm{ml}$ and post-radiation biopsy Gleason score 7 were considered a favorable risk group with $70 \%$ having longterm freedom from BCR [3]. SRARP is technically demanding. While outcomes have improved with better patient selection and greater surgical experience, the incidence of both bladder neck contracture $(30 \%)$ and incontinence (50\%) remain high; there is some suggestion that these complications may be reduced with minimally invasive RP, but further data are needed to confirm this observation [3].The improvements in surgical experience and the technical advances, including robotic surgery, have ameliorated surgical performances for salvage radical prostatectomy (SRP) over the last decade [4,5]. Erectile dysfunction and urinary incontinence were 32\%and 100\% [4]. Even with the limits of the retrospective studies, recent series of SRARP suggest its superiority over other salvage treatment modalities such as cryotherapy, HIFU [4]. The 5-year biochemical free probability rates after SRARP ranged between $28 \%$ and $71 \%$ [4]. Early diagnosis of this and aggressive treatment could produce better and more durable results than the other salvage approaches [6]. There is also no data available on pelvic lymph nodes dissection available for SRP. The Vattikuti Urology Institute published their series of 11 men who underwent SRRLP of which the biochemical free progression was $63 \%$ at a median follow-up of 20.5 months [7]. In the largest SRARP series, $67 \%$ of men had biochemical free progression at a median follow-up of 18 months [8]. Interestingly, of the patients who developed BCR after surgery, $67 \%$ had positive surgical margins and $33 \%$ had preoperative PSA $>10 \mathrm{ng} / \mathrm{ml}[8]$. Clearly, salvage robotic radical prostatectomy (SRARP) has better outcomes, than open robotic prostatectomy. This is especially relating to continence side effects. Previously, this could be as high as $50 \%$. However, with the advent of DaVinci surgical systems, this is significantly reduced. This allows the patient good oncological outcomes, whilst receiving a minimally invasive operation. The other difficulty, in general with open surgery, was the inability to do nerve sparing as with the robotic prostatectomy. This results in far higher rates of erectile dysfunction with robotic prostatectomy. Additionally, the positive margin rate is slightly lower with the robotic system with straightforward dissection of lymph nodes. Additionally, the complication rate for this procedure has far reduced with a robotic system. This has impacted on overall patient care, resulting in prostatectomies even being done as daycase surgery [9]. Whole gland salvage treatments such as radical prostatectomy and brachytherapy for recurrent prostate cancer after primary irradiation show severe toxicity rates [10]. Previously, high failure rates have been observed [11].

*Corresponding author: Sanchia Goonewardene, Guys and St Thomas' NHS foundation trust, London, West Midlands United kingdom, Tel: +020 7188 7188; E-mail:ssg7727@yahoo.co.uk

Received April 19, 2016; Accepted May 27,2016; Published June 06, 2016

Citation: Goonewardene S (2016) Salvage Therapy for Prostate Cancer: Which is Best? Brachytherapy versus Open and Robotic Prostatectomy. J Nucl Med Radiat Ther 7: 290. doi:10.4172/2155-9619.1000290

Copyright: (C) 2016 Goonewardene S. This is an open-access article distributed under the terms of the Creative Commons Attribution License, which permits unrestricted use, distribution, and reproduction in any medium, provided the original author and source are credited. 
Salvage radical prostatectomy is a technically challenging procedure. This is associated with a high complication rates for rectal injury, urinary leak anastomotic stricture and incontinence [12]. What cause the issues are extra-prostatic fibrosis, distorted anatomy and nonanatomical tissue-planes. Additionally, robotic-assisted salvage radical prostatectomy (SRARP) is not widely performed [13]. Focal therapy, such as salvage brachytherapy (SBrach) is alternative to salvage radical prostatectomy for locally recurrent prostate cancer after primary radiation therapy [14]. If patients can be selected properly, focal therapy could enable tumor eradication without the morbidity associated with salvage radical prostatectomy (14). We review the oncological and functional outcomes of SRARP to SBRACH. SRARP accounts for only $2.9 \%$ of expected RT local failures. SRARP patients undergoing surgery have more high risk disease. As part of this, patient expectations are key. Patients should be counselled regarding side effects, anastomotic leakage on cystogram, and prolonged catheterization times [15]. Additionally the time to potency and continence in SRARP undergoing partial and no nerve sparing was significantly delayed [15]. Perioperative complications of SRARP include urinary incontinence rates of $40 \%$ to $50 \%$ and rectal injury rates of $10 \%$ to $15 \%$. However, in the hands of an experienced surgeon, these figures will be significantly improved. Long-term disease-free survival rates of $30 \%$ to $40 \%$ can be expected [16]. The proportion of patients returning to potency and continence was also lower; however this tends to be more high risk disease. As a result patients showing high-risk disease characteristics should be informed adequately about the low chances of success [17]. Treatment results could be improved if salvage therapy is considered very early in the disease process. SRARP is technically possible and with limited perioperative morbidity [18]. This curative therapy may be underutilized in biochemical recurrence [19]. In select patients derived from a population-based cohort, SRARP resulted in effective local cancer control with acceptable perioperative outcomes [20]. However, there are factors that highlight how successful SRARP maybe. Interestingly, this cohort demonstrated PSA level $>20 \mathrm{ng} / \mathrm{ml}$ is associated with positive margins and prolonged length of stay after SRARP. Clinical stage T2 or greater disease is also associated with prolonged length of stay, whereas surgery at an experienced facility reduced this risk. Salvage radical prostatectomy (SRARP) is a potentially curative operation performed for recurrent prostate cancer [20]. Salvage radical prostatectomy is a technically challenging procedure that is associated with high complication rates for rectal injury, urinary leak anastomotic stricture and incontinence [21]. There can be extensive extra-prostatic fibrosis leading to distorted anatomy and difficulty with tissue-planes a difficult dissection. Robotic-assisted salvage radical prostatectomy is not widely performed but has specific advantages to the traditional open procedure. This allows for excellent visualization of tissue planes rather than feel, reduced bleeding and a more secure anastomosis [21]. Additionally robotic extended pelvic lymph node dissection is safe and can improve the accuracy of surgical staging. Salvage radical prostatectomy is a safe and effective alternative for the treatment of locally recurrent prostate cancer. In comparison to SRARP, few patients were considered for local salvage therapy after radiation failure, and only $2 \%$ received it [22]. There is also a possible underutilization of SBRACH after radiotherapy and indicate a need for more collaboration between tertiary care centres. SBRACH has a low rate of genitourinary side effects and no late gastrointestinal side effects [23]. The treatment efficacy in the first 3 years demonstrated good outcomes [23]. Prostate cancer recurrence is often bilateral and involves multiple zones. Additionally, it can be high grade, bulky and close to the urethra [24]. This suggests salvage focal therapy after radiation failure will be difficult [24]. Yet results demonstrate HDR-BT have good oncological outcomes
[25]. However, when comparing both groups SBRACH to SRARP, 5 -year BCR-free rates are superior in patients treated with SRARP [25]. Salvage brachytherapy for biopsy-proven local recurrence of prostate cancer is a technically feasible alternative for lower risk disease [26]. Improved biochemical relapse free survival occurs for lower Gleason score and pre-salvage PSA [27]. SBRACH is an effective salvage technique and can be considered in well selected patients allowing for dose escalation to- the nodular recurrence.This data confirmed the feasibility and safety of SBRACH when performed by experienced centers [28]. The disease control rates and complications of treatment compare very favorably with those reported using other modalities [29].

\section{Conclusions}

This overview shows clinical practice of prostate cancer salvage therapy. Failure and toxicity rates are observed, regardless of salvage technique. Whilst salvage brachytherapy is appropriate for low risk cases, and gives low toxicity, SRARP is better for high risk disease with better oncological outcomes. Patients should be selected with great care before offering these salvage treatment strategies.

\section{References}

1. Kuban DA, Thames HD, Levy LB, Horwitz EM, Kupelian PA, et al. (2003) Long-term multi-institutional analysis of stage T1-T2 prostate cancer treated with radiotherapy in the PSA era. International Journal of Radiation Oncology Biology Physics 57: 915-928.

2. Ahlering TE, Eichel L, Skarecky D (2005) Rapid communication: early potency outcomes with cautery-free neurovascular bundle preservation with robotic laparoscopic radical prostatectomy. J Endourol 19: 715-718.

3. Eastham JA, Carroll P, Pisters L, Nguyen PT, Touijer K (2012) Salvage therapies after radiation therapy. Urologic Oncology: Seminars and Original Investigations 30: 940-941.

4. Alongi F, De Bari B, Campostrini F, Arcangeli S, Matei DV, et al. (2013) Salvage therapy of intraprostatic failure after radical external-beam radiotherapy for prostate cancer: a review. Crit Rev Oncol Hematol 88: 550-563.

5. Pontes JE, Montie J, Klein E, Huben R (1993) Salvage surgery for radiation failure in prostate cancer. Cancer 71: 976-980

6. Amling CL, Lerner SE, Martin SK, Slezak JM, Blute ML, et al. (1999) Deoxyribonucleic acid ploidy and serum prostate specific antigen predic outcome following salvage prostatectomy for radiation refractory prostate cancer. Journal of Urology 161: 857-863.

7. Boris RS, Bhandari A, Krane LS, Eun D, Kaul S, et al. (2009) Salvage roboticassisted radical prostatectomy: initial results and early report of outcomes. BJU Int 103: 952-956

8. Eandi JA, Link BA, Nelson RA, Josephson DY, Lau C, et al. (2010) Robotic assisted laparoscopic salvage prostatectomy for radiation resistant prostate cancer. J Urol 183: 133-137.

9. Goonewardene SS, Rowe EW (2014) Radical robotic-assisted laparoscopic prostatectomy: a daycase procedure. J Laparoendosc Adv Surg Tech A 24 804-805.

10. Peters M, Maenhout M, Van Der Voort Van Zyp JRN, Moerland MA, Moman MR, et al. (2014) Focal salvage iodine-125 brachytherapy for prostate cance recurrences after primary radiotherapy: A retrospective study regarding toxicity biochemical outcome and quality of life. Radiotherapy and Oncology 112: 77 82.

11. Peters M, Moman M, Van Der Heide U, Moerland M, Franken S, et al. (2011) Focal salvage for prostate cancer recurrences. Radiotherapy and Oncology 99: 381

12. Tran H, Kwok J, Pickles T, Tyldesley S, Black PC (2013) Utilization of loca salvage therapy after primary radiotherapy for prostate cancer. J Clin Oncol 1.

13. Tran H, Kwok J, Pickles T, Tyldesley S, Black PC (2014) Underutilization of local salvage therapy after radiation therapy for prostate cancer. Urologic Oncology: Seminars and Original Investigations 32: 701-706. 
Citation: Goonewardene S (2016) Salvage Therapy for Prostate Cancer: Which is Best? Brachytherapy versus Open and Robotic Prostatectomy. J Nucl Med Radiat Ther 7: 290. doi:10.4172/2155-9619.1000290

14. Leibovici D, Chiong E, Pisters LL, Guo CC, Ward JF, et al. (2012) Pathological characteristics of prostate cancer recurrence after radiation therapy: Implications for focal salvage therapy. Journal of Urology 188: 98-102.

15. Bates AS, Samavedi S, Kumar A, Mouraviev V, Rocco B, et al. (2015) Salvage robot assisted radical prostatectomy: A propensity matched study of perioperative, oncological and functional outcomes. European Journal of Surgical Oncology 4:1540-1546.

16. Russo $P(2000)$ Salvage radical prostatectomy after radiation therapy and brachytherapy. J Endourol 14: 385-390.

17. Moman MR, Broers E, Van Der Poel HG, Vergunst H, De Jong IJ, et al. (2009) Salvage therapy in prostate cancer recurrences. Treatment outcome and toxicity after salvage prostatectomy, salvage cryosurgery or 125-I implantation: A multicentre experience from the Netherlands. European Urology, Supplements 8:301- 308.

18. Kaouk JH, Hafron J, Goel R, Haber GP, Jones JS (2008) Robotic salvage retropubic prostatectomy after radiation/brachytherapy: initial results. BJU Int 102: 93-96.

19. Abern M, Dude A, Latchamsetty K, Coogan C (2011) Salvage radical prostatectomy after radiation therapy. Journal of Urology 1: 1-68.

20. Pearce SM, Richards KA, Patel SG, Pariser JJ, Eggener SE (2015) Populationbased analysis of salvage radical prostatectomy with examination of factors associated with adverse perioperative outcomes. Urologic Oncology: Seminars and Original Investigations 33: 163-166.

21. Eldred-Evans D, Sturch P, Cahill D, Dasgupta P, Challacombe B, et al. (2013) Salvage robotic-assisted radical prostatectomy: Challenges and solutions. Urology 1: 170
22. Tran H, Kwok J, Pickles T, Tyldesley S, Black PC (2014) Underutilization of local salvage therapy after radiation therapy for prostate cancer. Urol Oncol 32: 701-706.

23. Lahmer G, Lotter M, Kreppner S, Fietkau R, Strnad V (2013) Protocol-based image-guided salvage brachytherapy. Early results in patients with local failure of prostate cancer after radiation therapy. Strahlenther Onkol 189: 668-674.

24. Leibovici D, Pagliaro L, Rosser CJ, Pisters LL (2005) Salvage surgery for bulky local recurrence of prostate cancer following radical prostatectomy. J Urol 173 781-783.

25. Bohm K, Lesmana H, Schiffmann J, Larcher A, Schwarz R, et al. (2015) 5-years biochemical recurrence and overall survival rates after radical prostatectomy or high dose radiation brachytherapy with additional external beam in patients with clinically localized prostate cancer. European Urology, Supplements 14 e513-ea.

26. Traudt K, Ciezki J, Klein EA (2011) Low-dose-rate brachytherapy as salvage treatment of local prostate cancer recurrence after radical prostatectomy. Urology 77: 1416-1419.

27. Kumar AM, Traudt K, Ciezki JP, Reddy CA, Klein EA (2011) Brachytherapy as salvage treatment for local nodular recurrence of prostate cancer. J Clin Onco 29: 86.

28. Gastaldi E, Gallo F, Chiono L, Giberti C (2014) Salvage low-dose-rate brachytherapy for prostate cancer local recurrence after radical prostatectomy: our first three patients. Urologia 81: 46-50.

29. Tharp M, Hardacre M, Bennett R, Jones WT, Stuhldreher D, et al. (2008) Prostate high-dose-rate brachytherapy as salvage treatment of local failure after previous external or permanent seed irradiation for prostate cancer. Brachytherapy $7: 231-236$. 